\title{
Living in a Sociomaterial World
}

\author{
Eric Monteiro ${ }^{1, *}$, Petter Almklov², and Vidar Heps $\emptyset^{3}$ \\ NTNU, Dept. of Computer and Information Science (IDI), 7491 Trondheim, Norway \\ ericmeidi.ntnu.no \\ 2 \\ Studio Apertura, NTNU Social Research, Dragvoll, 7491 Trondheim, Norway \\ pettera@svt.ntnu.no \\ 3 NTNU, Dept. of Applied Geosciences, 7491 Trondheim, Norway \\ vidar.hepso@ntnu.no
}

\begin{abstract}
The Internet of Things (IoT) - the proliferation of networked sensors, gadgets, artefacts and measurement devices - increase the presence, scope and potential importance of mediated information in collaborative work practices. This underscores the material aspects of sociomaterial practices. We study an extreme case where work practices rely heavily, almost entirely, on representations. In line with the research programme on sociomateriality, we acknowledge the performative role of representations. Representations are thus actively embedded in practice rather than passive re-presentation of data. Extending the programme of sociomateriality, we contribute by identifying and discussing three strategies detailing how sociomaterial practices get performed: extrapolate (filling in gaps), harmonise (ironing out inaccuracies) and abduct (coping with anomalies). We draw empirically on a longitudinal (2004-2011) case study of the subsurface community of NorthOil. This community of geologists, geophysicists, reservoir engineers, production engineers and well engineers rely on sensor-based (acoustic, electromagnetic, radioactive, pressure, temperature) data when exploring and producing oil and gas resources several thousand meters below the seabed where direct access to data is difficult and/ or limited.
\end{abstract}

Keywords: Sociomateriality, performativity, representation.

\section{Introduction}

Sociomateriality is a label for a research agenda into the conceptualisation of the interplay between (material) technology and (human) use [1]. Rather than an independent theory or set of concepts, sociomateriality summaries and highlights salient aspects and insights gained in information systems research over the last couple of decades, emphasising the inherent contingency involved with enacting technology [2, 3], the considerable discretion for users [4, 5] and the modular/ interconnected/ networked nature of ICT [6].

A defining feature of sociomateriality, stemming from its commitment to the 'entanglement' of human and material practices [1], is to dismiss a representational

* Corresponing author.

A. Bhattacherjee and B. Fitzgerald (Eds.): Future of ICT Research, IFIP AICT 389, pp. 91-107, 2012.

(C) IFIP International Federation for Information Processing 2012 
view of technology in favour of a performative one. Here the meaning (hence use) of representations is neither fixed nor stable but emerge through practice (as they are 'performed'). Representations, then, are not passive re-presentations but active, constitutive features of (sociomaterial) practice.

Building on, but ultimately extending, the research programme of sociomateriality, the purpose of our paper is to identify and discuss how practice get entangled with technologically mediated representations i.e. we study the strategies at play. Sociomateriality states that use/ technology is entangled; we analyse how these entanglement play out. We empirically identify three strategies of entanglement: extrapolate (fill in the gaps), harmonise (sorting out errors and inaccuracies) and abduct (coping with anomalies). We have consciously selected an extreme case where work practices are saturated by ICT based visual and textual representations of the data, a consequence of access to the 'reality' (i.e. referent, in a representational vocabulary) being either unattainable or very limited. Moreover, the work practices we study matter: their implications pose significant risks to economic value, the environment and human safety as made painfully clear by Obama's commission following the Deepwater Horizon blowout [7]. Empirically we draw on a longitudinal (2004-2011) case study of work practices within the so-called subsurface community in NorthOil (a pseudonym), a community crucial to efficient, innovative and safe oil and gas exploration and production.

\section{Conceptualising Technology: Sociomateriality in Context}

The discourse on how to conceptualise technology runs long in information systems research. As a counter-reaction to overly deterministic accounts, the significant discretion for users to appropriate information systems was established decades ago from both empirical studies [2, 5, 8] and theoretical concepts (e.g. the 'situated' nature of action proposed by Suchman [4]), the presence of 'workarounds' by Gasser [5] and Giddens' structuration theory as proposed by [9]). In their historical recapitulation, Orlikowski and Scott [1] describe three, broad categories of approaches: (i) discrete entities (with uni-directional causal effects of technology), (ii) mutually dependent ensembles (with bi-directional relationship) before outlining (iii) sociomaterial assemblages. The decisive distinction between the former two and the latter, Orlikowski and Scott (ibid., p. 455) point out is that the latter see "tools...as constitutive of both activities and identities".

Sociomateriality is a 'banner' or 'signal' (opus cit., pp. 455 and 456) for this agenda rather than an independent theory in itself. In our perspective, the thrust of insights of sociomateriality is essentially drawn from science and technology science (STS), especially actor-network theory. The constitutive use/ technology entanglement defining sociomateriality, corresponds exactly to the 'strong principle of symmetry' found in actor-network theory [10, 11]. Illustrating actor-network theory based work in information systems research prior to [1], Quattrone and Hopper [12, p. 216] explain how "agency and an object's identity reside neither in an individual nor a technology but in a chain of relations between actors (and actants)". Similarly echoing the principle of symmetry between the social and the technical, [13] 
discusses the 'inscription' of behaviour (i.e. agency) into a variety of materials including technical standards, habits and training programmes.

The constitutive entanglement [14] of use/ technology embedded in the notion of performativity is a "central idea entailed in" [1, p. 460]. We argue this insight was arrived at prior to its formulation within sociomateriality. That use/ technology is entangled is a shared insight with e.g. STS. The true, remaining challenge is how to push further, how to explore entanglement in more detail.

An interesting avenue of the pursuit of performativity is the emphasis on extreme cases i.e. cases where representations (constitutively entangled with practice) saturate or dominate the empirical settings. In STS, this has for some time prompted a strong interest in work settings relying heavily, at times almost entirely, on representations. The work-settings thus take on an almost semiotic character. Knorr-Cetina's [15] study of high-energy physicists illustrates this well. Studying the behaviour of (sub)particles that are inaccessible by direct means, the empirical material of highenergy physicists is exclusively drawn from visual and numerical representations extracted from the apparatus surrounding particle accelerators. The heavy reliance on sensor and measurement devices - inherently error-prone - is challenging [16]. Sensors decay, contain bugs or need calibration. This dilemma is central also to our case from the oil and gas sector. Another setting attracting STS attention is electronic markets [17]. The work practices of traders lean heavily on the real-time representations (readings, computational analysis, visualization) of selected events in the electronic market. In a widely cited study of the option market, MacKenzie and Millo [18, p. 107], cited in [1, p. 461]) explicitly set out to demonstrate the performativity of a formula (the so-called Black-Scholes model) by that it "succeeded empirically not because it discovered pre-existing price patterns but because markets changed in ways that made its assumptions more accurate and because the theory was used in arbitrage".

What the STS studies compellingly demonstrate is the constitutive entanglement of use/ technology. This provides strong empirical evidence for sociomateriality. What remains elusive, however, and the aim of our paper, is to spell out the structure and content of entanglement. We analyse the sociomaterial practices of a subsurface community focusing on how they develop, maintain and revise so-called reservoir models. Operating in an almost semiotic world, the subsurface community have to live with the imperfections, glitches and shortcomings of the reservoir model stemming from its input from incomplete, error-prone and uncertain sensor-based data.

\section{Method and Case}

\subsection{Approach and Access}

We employ an interpretative approach that is geared towards an understanding of the context of the information system and the process over time of mutual influence between the system and its context. A deep-seated conviction we held was that a longitudinal case study was crucial for providing the level of detail that we sought regarding the process of organisational dynamics [19]. In line with [20, p. 537]'s 
advice for facilitating generalisations from case studies of single organisations, we relied on a theoretical sampling of the case site. We were actively seeking a work setting where the performativity of representations would stand out due to the particularly heavy reliance on representations: we selected a case where 'direct' access to the data referred to was cumbersome at best.

The selection of the organisation for the case study was also influenced by pragmatic concerns of access; we know NorthOil well. The first author is an experienced IS researcher with a prolonged research project portfolio within NorthOil e.g. a study of standardization of well maintenance. The second author has an MSc in geological engineering, and based his $\mathrm{PhD}$ in social anthropology on a yearlong ethnographic fieldwork in the subsurface departments of one of NorthOil's field organisations. He has since worked on several (applied) research projects within the Norwegian petroleum industry. The third author has been an employee of NorthOil for 20 years. He has been involved in a variety of projects in and around the subsurface community. He was involved in intervention-oriented research projects as part of his fieldwork for a PhD within NorthOil.

\subsection{Data Collection}

Pollock and Williams [21] point out the importance of broad, longitudinal research designs to allow for what they call the biography of a technology (artefact) to supplement what dominates interpretative IS research viz. the single site case study of an implementation. Given the all too real constraints on research projects - they have confined time spans, they are targeted at given issues, involved $\mathrm{PhDs}$ have time constraints for delivery - Pollock and Williams (ibid.) propose a 'synthetic' form of longitudinal case study where formally independent research projects by the research group is chained together to make a bigger picture. Continuity is achieved by maintaining continuity in research approach, overall themes and transparency in documentation. Our study follows Pollock and William's (ibid.) proposed form of a longitudinal case $(2004-2011)$. We rely on three types of data collection that ran in parallel: participative observations, semi-structured interviews and document studies (details in Table 1).

Participative observation was of different types. Predominately conducted by two of the authors, we have participatory observations from subsurface operation centres, departments and on offshore rigs. One author has participated in asset workshops where future production plans are discussed. Participatory observations provided insight into everyday practices as we followed people around, informal chatting over coffee, attending meetings and work at their desks.

Interviews were semi-structured and lasting 45 minutes - 1,5 hours. Some have been interleaved with participatory observation, as a way to clarify and expand on observations. Seven selected interviews particularly discussing the use of the reservoir model in operational settings have been fully transcribed. 260 pages of field notes were written during observations and the interviews closely linked to the observations. 
Document study of both paper based but more importantly electronic documents have been conducted. Electronic documents include electronic archives, database readings, PowerPoint presentations, well plans, email discussions and policy- and operational regulations.

Table 1. Overview of the three modes of data collection: participatory observations, interviews and document study

\begin{tabular}{|c|c|}
\hline Participatory observations & $\begin{array}{l}\text { - Participatory observation of production } \\
\text { optimization } 18 \text { days during } 3 \text { months in } 2005 \\
\text { - Participatory observation of product optimization } \\
\text { of another asset for } 14 \text { days during } 4 \text { months in } \\
2006 \\
\text { - Participant observations } 3 \text { months in } 2004 \text { every } \\
\text { day of one of the assets } \\
\text { - Two field trips to offshore installations, } 5 \text { days in } \\
2007 \\
\text { - Participatory observation of subsurface } \\
\text { - } \text { departments, } 4 \text { days during } 2008-2010 \\
\text { - Participatory observations from } 4 \text { asset workshops } \\
\text { meetings and discussions with subsurface and } \\
\text { management (2004 - 2011) }\end{array}$ \\
\hline Semi-structured interviews & $\begin{array}{ll}- & \text { IS/ IT management: } 13 \text { interviews } 2005-2010 \\
\text { - } & \text { Subsurface members: } 55 \text { interviews } 2004-2011\end{array}$ \\
\hline Documents & $\begin{array}{l}\text { Electronic archives (presentations, memo, } \\
\text { documents) } \\
\text { - } \quad \text { Database readings (from subsurface tools) } \\
\text { - } \quad \text { Email discussions } \\
\text { - } \quad \text { Extranet: policy- and operational regulation } \\
\text { - }\end{array}$ \\
\hline
\end{tabular}

\subsection{Data Analysis}

We alternated between data collection and analysis. Following van Maanen's [22] suggestion, we made extensive use of field notes, making sure to separate 'raw' data from own comments, reflections, and questions. Given that all authors, albeit unequally, were involved in both data collection and analysis, we were able to conduct numerous sessions comparing, contrasting and challenging each other's (preliminary) interpretation, thus enjoying the benefits noted by [20, p. 538]. The three authors of this paper have over a period of more than a decade worked 
together in various configurations of research collaboration. Though collaboration has been in bursts rather than continuous, we are fairly close research partners. By using temporal bracketing and graphical process maps, which are two strategies for data analysis that were proposed by [23], we generated visual illustrations of how the chronological development, including technology implementation projects, within the subsurface community resonated with broader themes and trends within NorthOil.

Beyond internal discussions, our data analysis relies on a series of workshops, meetings, and informal discussions with NorthOil managers, subsurface members, IT department, in which we presented our findings and preliminary data analysis. This contributed importantly to an external validation and criticism of our analysis. For example, when presenting empirical findings on how one reservoir model is used operationally, professionals will often contrast our findings with how things are done differently at other fields. Thus we are painfully aware that our account, complicated as it may be for outsiders, of how the reservoir model is used operationally is simplified and stereotypical.

In our data analysis, we strived to adhere to Klein and Myers' [24] principle of multiple interpretations. This hinges crucially on an ability to discern distinct, potentially diverging, voices among the actors. An example of the results of our efforts in this direction is that the differences between the subsurface community and management when it comes to reservoir estimates, a highly political assessment. Also within the subsurface community clear differences in perspectives were manifest. An example of this is the difference in perspectives between drilling engineers, who wants a clear-cut drilling target in order to build an operationally robust drilling project, and the geologists and reservoir engineers, who often want to keep options open for eventualities and opportunities that may appear during operations.

We utilized the added flexibility in data collection that results from overlapping data collection with analysis [20]. Our data analysis moved between inductively generating aggregated categories from codes (manually: using colour, post-it notes, annotations) and drawing deductively on prior theoretical ideas, notably actor-network theory. We were thus anything but clean slates [25]. The first construct in our theoretical template underpinning our analysis (see Table 2: extrapolate) drew inductively on aggregated categories on practices of navigating in extensive but ill-structured historical data, and resonated with notions of workarounds and improvisation known from practice-based research. The second construct (harmonise) drew inductively on aggregated categories about heuristics for producing trustworthy information that resonates with performativity found in actor-network theory. The third construct (abduct) is drew inductively on break-down situations where 'small' observations challenge overall understanding. This ties in with the way subsurface members in general and geologist in particular collectively arrive at interpretations [26]. 
Table 2. Our interpretative template with the 3 constructs underpinning our analysis

\begin{tabular}{|l|l|}
\hline Construct & \multicolumn{1}{|c|}{ Illustration } \\
\hline Extrapolate & $\begin{array}{l}\text { In the absence of complete data sets, e.g. when } \\
\text { you have but a few wells in designated locations } \\
\text { but nothing in-between, "you interpolate between } \\
\text { these wells" }\end{array}$ \\
\hline Harmonise & $\begin{array}{l}\text { Smaller inconsistencies or outright errors are not } \\
\text { worth spending a lot of time and resources to iron } \\
\text { out e.g. "Local changes based on single } \\
\text { observations in new wells are, at least on fields } \\
\text { with fairly complex models, often too resource } \\
\text { demanding to integrate into the [reservoir] model". }\end{array}$ \\
\hline Abduct & $\begin{array}{l}\text { When "data doesn't make sense" there is } \\
\text { sometimes a need for a more fundamental new } \\
\text { understanding of the reservoir e.g. "this fault [line] } \\
\text { has been misinterpreted. It's shifted downwards, } \\
\text { not upwards. The faults we see here are the results } \\
\text { of a landslide pattern". }\end{array}$ \\
\hline
\end{tabular}

\subsection{Case Context: The Reservoir Model}

NorthOil (a pseudonym) is a company in northern Europe with some 30.000 employees operating in about 40 countries worldwide. The focus in this paper is on the work within the subsurface community in NorthOil. The subsurface community is involved intimately with the core value generating activities of any $\mathrm{O} \& \mathrm{G}$ company as they are principally responsible for locating commercially interesting fields, planning, development and optimizing daily production. Subsurface departments consist of numerous specialized disciplines: geophysicists, geologists (with different sub-specialties), reservoir engineers, production engineers, drilling engineers and well completion engineers to name the most common. The subsurface professionals partly work in interdisciplinary teams co-located around the different $\mathrm{O} \& \mathrm{G}$ field organizations and partly in disciplinary defined networks cutting across geographically separated field sites.

The empirical focus of our paper is on the reservoir model. It consists of grid cells ascribed with a set of properties based mainly on interpretation of geological data. The model in Figure 1 consists of roughly 45.000 active cells. Information about the reservoir is fragmented and incomplete. The reservoir model is a concerted effort of creating one model representing the whole reservoir. The grid cells of a model are, depending on geology and available data, "about the size of this office building".

NorthOil's fields are predominantly deep-sea hydrocarbon reservoirs most commonly located 1500-3000 meters below the seabed. The hydrocarbons are contained in Jurassic sandstone buried over millions of years by layer upon layer of new sediments. Wells are drilled from concrete platforms, floating rigs or ships. With current drilling technology it is possible to hit a defined target with a precision in the magnitude of meters. To make use of the accuracy in drilling, the reservoir model also 


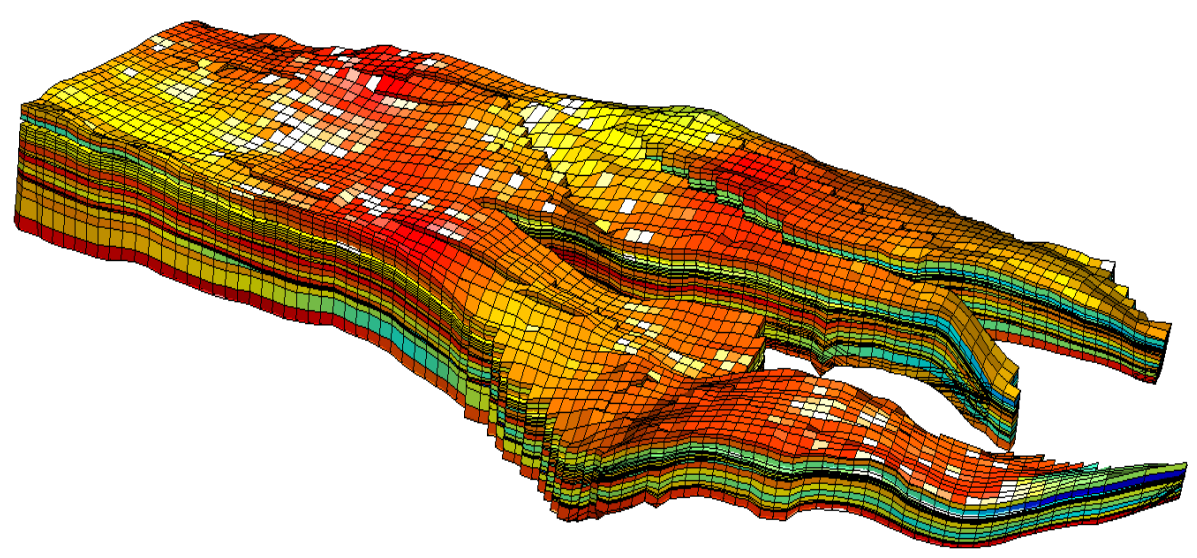

Fig. 1. Visual representation of a reservoir model

need to be fine-grained hence enormous efforts are invested into new technologies and methods in reservoir description. The pace of innovation is high, especially in the ongoing "digitalization" of the industry. Three main types of sensor-based data are essential to the subsurface community.

Seismic data are digital recordings of the reflections of acoustic waves sent down to the reservoir in seismic surveys. It is a very advanced echogram, able to "see through" at least thousands of meters of overlying rock. By specific arrangements of sound sources and microphones and extensive computer processing, geophysicists are able to outline layers and other structures in the rock based on contrasting acoustic properties (see Figure 2, left picture). Most importantly, such contrasts reveal density differences between porous and non-porous rock, the former being more likely to contain hydrocarbons. The data sets from modern seismic surveys are normally threedimensional and they cover the whole volume of a reservoir. The main weakness of seismics is the low resolution, at best around 30 meters.

Well $\log s$ are collections of sensor-based measurements from logging assemblies lowered into the wells, normally in connection with drilling or well operations. The sensors measure physical properties associated with geological properties, e.g., gamma radiation is higher in shale than in sand stone and electrical resistivity is higher in oil than in water. The log plots different measurements and observations along the well (see Figure 2, middle picture) along a downward axis representing length of the well.

Production data are real-time measurements of the oil and gas, volumes transported out of (and in the case of injection for pressure support, pumped into) the reservoir. These can be plotted in various ways, for example as in Figure 2 (right). The pressure development in the reservoir also is monitored. These data give the subsurface group clues about how much oil there might be left in the reservoir, and aid them in day-to-day optimizing existing wells and planning production. 

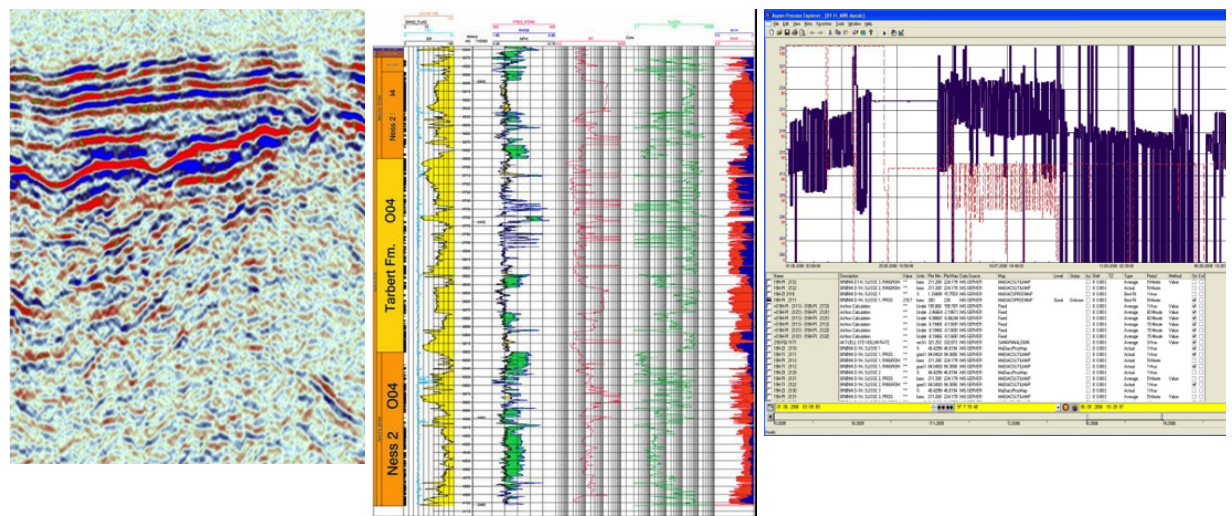

Fig. 2. Typical visual representations of the 3 principal types of data: seismic data (left), well $\operatorname{logs}$ (middle) and production data (right)

Building a reservoir model is an extensive project lasting months to years. The model (Figure 1) is used throughout the lifetime of the field to simulate fluid movement in the reservoir, and it is updated by history matching towards recorded production data. Our informants willingly admit to the shortcomings of the reservoir model: "The only thing we know for sure is that the [reservoir] model is wrong". Our concern with the reservoir model is how this imperfect representation gets entangled with, and is constitutive of, everyday work practices.

\section{$4 \quad$ Results}

\subsection{Extrapolate: Filling in the Gaps}

Modelling the reservoir is a creative endeavour where the reservoir is conjured into existence by active interrogation of the available data. We analyse how detailed observations with coarse remote sources are combined in creative extrapolations into the unreachable volumes, between and beyond well observations and beneath the resolution of remote sources.

Wells are just thin lines of high quality data points in kilometre-wide reservoirs. These are interpreted in combination with the vague patterns seen on the seismics. A geologist explains how he proceeds to build an understanding of a new reservoir that has only three wells:

"Obviously, if you have three wells they're going to tell you a lot about the vertical [well paths]. So you have at least the understanding of the vertical sense of the layers and you can build your sedimentological understanding... You have three wells and ... you try to interpolate between those wells with your information and then you try to extrapolate away from those wells into areas that are further away. And then with the help of the seismic, you try to calibrate and use the seismic to help you, and then come up with some sort of feeling about whether, you know, how much reservoir you've actually captured with the data you have?" 
Individual have some value of their own in specific situations, but it is in the combinations of data that conceptions of the reservoir as an entity are constructed. This is concretely manifested in the $\log$ as a visual representation: The individual measurements of radioactive and electrical parameters plotted on the log do not primarily speak directly of the geology themselves; rather it is certain patterns in the combinations of the different measurements that reveal the reservoir behind them. The $\log$, as a visual presentation also promotes specific combinations. Maybe the most striking example of this is shown in Figure 3. The measurements of two independent physical properties are superimposed on the plots with their scales adjusted so that the one is higher in sand and the other in shale. Thus, when the curves cross, it represents a transition between shale and sand, and the space between them will be green (representing shale) when one is higher and yellow (representing sandstone) when the other is higher. Like in the tale of seven blind Indians and an elephant, each sensor picks up only fragments of the reservoir, but when combined based on theory and experience their referent appears.

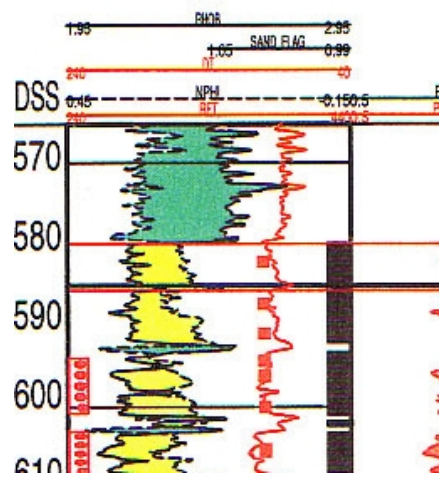

Fig. 3. A section of a well log superimposing two independent measurements, gamma radiation and neutron density. The axes of these measurements are adjusted to make the lines intersect, and the area between them change colour, when there is a transition from shale to sandstone. Thus, only a glimpse on the readings will indicate sandstone (yellow) or shale (green).

New, detailed information from the well path gives a lot of information about the surroundings beyond its actual range, if one is able to interpret it in combination with the seismic of the general structures in the area. We have on several occasions observed collective interpretation where boundaries are drawn in the reservoir based on such combinations. A typical example is when a well log displays a transition from tight shale to sandstone at a certain depth. If the depth corresponds with a reflection on the seismic chart, the well observation "confirms" the seismic and one may assume that the reflection represents this transition. Consequently, one can assume that the areal distribution of the seismic reflection represents the boundary between two layers, and one can, more speculatively guess that the properties of these volumes, for example the porosity of the sand stone, are represented by the properties registered in the log. 


\subsection{Harmonise: Resolving Inaccuracies and (Smaller) Inconsistencies}

The subsurface professionals cope with imperfect representations of the reservoir every day. One way of coping is by making informal adjustments or selectively dismissing inconsistent data. We discuss practices by which smaller inaccuracies, errors and inconsistencies are handled, not primarily to represent the reservoir better, but rather to respond to the organizational need to get on with work.

As information arrives from new wells and from production data, the reservoir model should ideally be updated to fit this information. However, local changes based on single observations from new wells are normally too resource demanding to fit into the model. Local changes may have ripple effects to connected areas of the reservoir:

"[Then] we have to figure out, how the heck are we going to update this monster? Because, if you start fiddling with two wells, then you do something with the rest as well."

The most common way of updating reservoir models, and a method that is subject to much current research, is history matching. History matching is basically a mathematical method where the static properties of the reservoir model are adjusted to best fit the actual historical (dynamic) production development. This operation is very demanding in terms of computer processing resources. It is also demanding in terms of manual labour with programming and constraining of the mathematical problem, so that the resultant history matched model makes sense geologically:

"Without history matching the model is just an academic exercise with little practical predictive value. When we get production data [..] we actually find out if things match or if the model fits reality."

However, the resultant model will not be perfect and "[i]n the end it is almost always the case that the history matched models violate some important geological constraints". History matching is a calibration of the model towards measured production and will, if it is successful, improve the accuracy of the model. Still, one of our informants stresses that the updated model is not something that passively represents the reservoir:

"[I]f we can do history matching that is the best. Because then you learn something about the flooding processes in the reservoir, in the process. But that doesn't mean that you should use the model afterwards [laughs]. It is the understanding, the understanding of the reservoir, which is important to gain from it. And if you have that, then a good engineer will be able to work intuitively with the model he has in his head and be able to do much of his work"

The understanding of the reservoir is relatively robust in the sense of being able to absorb both contradictory and missing data. Given the truly extensive network of sensors and measurement devices and the considerable physical stress they are subject to, equipment is anything but fault-proof. One informant explained how they resolved errors generated from erroneous equipment:

"We've given up fixing that choke. It's too costly to replace. I tell [the production engineer] that he simply has to shut his eyes and disregard the readings from it." 


\subsection{Abduct: Challenged by Anomalies}

In this section we discuss what happens when new information radically challenges the existing knowledge of the reservoir. We observe that whereas local ad hoc interpretations of new data can be creative and open ended, the reservoir model has a certain inertia upheld by workarounds and other modifying practices.

The model of the reservoir may be challenged in many ways. We illustrate contradictions stemming from information from well logs from new wells. Drilling a new well is the moment of truth for subsurface specialists. They may have planned wells for years. In the course of a few days when the drill bit with its logging sensors penetrates the reservoir, their interpretations and predictions are tested. The results will hardly ever fit their expectations, and they always imply adjustments of their ideas of the reservoir:

"But when we begin to drill, the only thing we know from all our experiences is that when we drill we find out things are not the way we think they are. "

One of the authors did his fieldwork at a subsurface department when several wells were drilled Though the field is one of the most studied on the continental shelf, with logs and production data from over 100 wells, each well contributed with new information. Most of the time, new well data meant that they had to make smaller adjustments but on a few occasions the well log, as it ticked in meter by meter, left the whole group in utter confusion. At the time of the fieldwork, most wells were drilled on the fringes of the reservoir. The geological theory of the area is that when the reservoir was a mountain on dry land, some large blocks on its fringes have loosened and slid downwards. Though located on one of these fault blocks, the well was expected to penetrate the common stack of known sedimentary layers in the reservoir. As drilling progressed, however, the observed geology "did not make sense". Expected sandstone-layers were "missing" and they lost track of "where they were" in the stratigraphic layers. Unexpected data during drilling was commonplace (cf. previous sections), but this was one of the rare occasions where it seemed impossible to make sense of it. The communal workroom of the geologists turned into a hothouse as experts and the curious seeped in from the entire department, conducting discussions along several paths. Some were discussing technical issues, like whether the positioning equipment in the drill string could be damaged. A geologist commented that the log looked upside-down and suggested that the fault block may have been rotated. Some tried to look at details in the log for a positive identification of the zones they had penetrated. Some discussed (more or less) similar situations with other well projects and the outcomes of those. Taken-for-granted assumptions were critically revisited. The project manager for the new well rather briskly tried to keep the crowd away as he studied the seismics intensely, shifted perspectives and visualization modes on his screen to study a vague vertical shape. He pointed at the screen and concluded, "this fault has been misinterpreted. It's shifted downwards, not upwards". This error did not in itself explain the data directly, but it supported a hypothesis, that the geologist explained later on. The fault was indicative of a certain landslide pattern that he had seen on a field trip to another geological site. According to this understanding there could be several smaller faults beneath seismic resolution (thus invisible) associated with the fault he could see. One of these smaller faults 
could have shifted the rock structures in a way that could explain the strange data. He drew on a piece of paper and told a geological story of how a major landslide had resulted in a pattern of smaller faults in the block. Gradually new data strengthened his hypothesis. When confronted by anomalies that challenge not only details of their understanding, but also whether they understand anything at all, all resources are drawn upon including field visits to geological fields on dry land in England.

\section{Discussion}

Proclaiming the performativity of sociomateriality is in itself not very bold. Our analysis is intended as a necessary detailing of sociomaterial practices. How, then, to characterise the emerging performativity?

Representations simplify. The subsurface community are painfully aware of the many details, nuances and variations lost when captured in the representations. Latour [27, p. 71] makes a relevant observation when discussing trade-offs, i.e. what you gain and what you loose, related to his notion of a circulating reference. Reporting from a team of researchers' efforts to analyse certain developments in the Amazon rainforest (whether a designated area of the forest was expanding or retreating), the scientists employ a number of different representations for the 'same' section of the forest: embodied observations from the area, dividing the forest into a grid pattern to select designated cells of forest, a sample of earth from one cell and a set of measurement/ tests from that sample. The richness of the former representations gets successively traded for increased mobility and ease of communication in the latter. Geologists are systematically trained, to use Latour's notion, to move up and down the steps of a circulating reference i.e. moving back and forth between rich representations to abstracted models/ representations. The touch and feel of the reservoir, its structures and tactile qualities, and its scale and complexity are not presented to their bodies and perception, and must be conjured out of the data. Figure 4 shows a picture from a field trip where geologists travel to 'analogous' sites to the $\mathrm{O} \& \mathrm{G}$ fields they are primarily interested in.

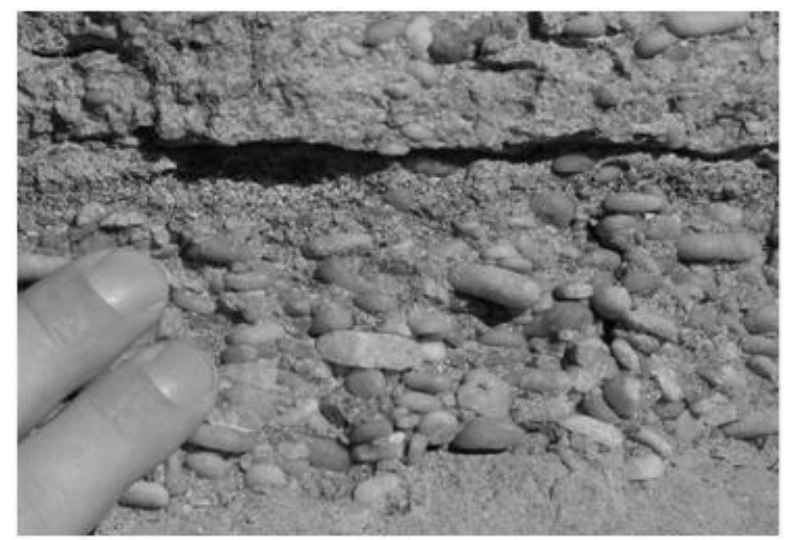

Fig. 4. Tactile experience of the porosity and permeability of the rocks from geologists' field trip to an analogue field accompanied by one of the authors 
The reservoir model is largely taken for granted in the sense that there is no anxiety over the fact that it is not 'real'. The subsurface community are of course acutely aware of the many shortcomings, inaccuracies, inconsistencies and debatable assumptions embedded in the representation, but the strategies dubbed extrapolate and harmonise in the previous section demonstrate vividly how far they are willing to press the reservoir model. The construction of the reservoir model needs to be understood in light of its purpose. Given the very significant resources involved in revising it ("we do it perhaps every tenth year"), the reservoir model functions like a kuhnian paradigm insofar as being robust despite conflicting data. Rather than spending valuable resources keeping the reservoir model up to date with the latest data, the performativity is strikingly pragmatic: you happily sacrifice perfection and completion of the representation for something good enough for the purpose at hand. The representations are expected to answer the pragmatic question par excellence, what to do next? Are the predicted volumes big enough to justify the cost of a new well? Should they drill or not?

Relying on representations presuppose trustworthy representations. Why should anyone trust representations positively known to neither accurate nor complete? Trustworthiness, as pointed out by scholars [28, 29], is not an attribute of the data but an acquired quality (a performed achievement, if you want). The underlying performances in NorthOil's subsurface community include: triangulating between different representations and data sources (e.g. during history matching when the reservoir model is calibrated with real-time production data), maintaining multiple versions (including historicised ones) of the data (e.g. when some engineers make and rely on a stock of private and local data and analysis) and, arguably the ultimate safety net, numerous formal and informal arenas to collectively discuss, assess and converge on interpretations of the representations (e.g. the weekly meetings between reservoir and production engineers on production optimization or during asset management workshops).

Radical, discontinuous changes in the in the interpretations of representations rely on an ability, systematically harnessed, to zoom in and out of representations i.e. to move from detailed accounts to the larger picture. This ability is manifest on different levels. At an analogous site, one geologist explained why sketches were often more useful than photographs:

"Photography makes things simpler but might lead to situations where you do not see the big picture and significant issues. One has to develop clear mental pictures of the structure up front."

The drawings are not mere low-resolution images, but have representational qualities of their own, emphasizing the 'big picture' and 'significant issues'.

\section{Conclusion}

The proclaimed performativity of sociomateriality is in itself valuable but inadequately specific for compelling theoretical, methodological and practical 
implications. Our detailing into three strategies is intended as a necessary step towards a more fine-grained grasp of the 'entanglement'.

As in STS, also IS research demonstrates an increased attention to settings saturated by representations. Supplementing what has traditionally been a cornerstone of IS research - workplace oriented studies and the role of technology - more mediaoriented studies are emerging. For instance, [30] reports from an ethnography of the practices and presentation of identities of game-playing users of the online game World of Warcraft (WoW) and [31] explore the embodied character of avatars in virtual space. An important motivation for our paper is the relative paucity of workoriented studies of the performativity of sociomateriality. This underscores Barley and Kunda's [32] point of "bringing work back in". We focus on the strategies of performativity in work-practices saturated by representations. Hence the purpose of our study is to analyse how performativity - in a work setting with cross-pressure from managerial obligations for efficiency, safety issues and professional identity [33] - is shaped.

Practical implications that follow from our work are related to perspectives on safety as known from the notion of high-reliability organisations (HRO). Though not explicitly addressing safety in this paper, our observations of the work of the subsurface professionals display clear HRO characteristics. The reservoir models, so central to everyday practices and operational decisions, are never really taken-forgranted. They are constantly, to use HRO vocabulary, willing and able to suspend simplifying assumptions. Left to themselves, studying the reservoir, workers display a "reluctance to simplify interpretations" and a "preoccupation with failure", important aspects of the "collective mindfulness" making up the cornerstone of HRO [34].

\section{References}

1. Orlikowski, W., Scott, S.: Sociomateriality: Challenging the separation of technology, work and organization. Academy of Management Annals 2, 433-474 (2008)

2. Kling, R.: The control of information systems after implementation. Comm. of the ACM 27, 1218-1226 (1986)

3. Orlikowski, W.: A Practice Perspective on Technology-Mediated Network Relations: The Use of Internet-Based Self-Serve Technologies. Information Systems Research 15, 87-106 (2004)

4. Suchman, L.: Plans and situated action. University Press, Cambridge (1987)

5. Gasser, L.: The integration of computing and routine work. ACM Trans. on Information Systems 4, 205-225 (1986)

6. Pentland, B., Feldman, M.: Narrative Networks: Patterns of Technology and Organization. Organization Science 18, 781-795 (2007)

7. National commission. BP Deepwater Horizon oil spill and offshore drilling, Report to the President by the National commission (2011), http: / / www. oilspillcommission.gov/final-report

8. Barley, S.: Technology as an Occasion for Structuring: Evidence from Observations of CT Scanners and the Social Order of Radiology Departments. Administrative Science Quarterly 31, 78-108 (1986) 
9. Orlikowski, W., Robey, D.: Information Technology and the Structuring of Organizations. Information Systems Research 2, 143-169 (1991)

10. Scott, S., Wagner, E.: Networks, negotiations, and new times: the implementation of enterprise resource planning into an academic administration. Information and Organization 13, 285-313 (2003)

11. Walsham, G.: Actor-network theory and IS research: current status and future prospects. In: Lee, A.S., Liebenau, J., DeGross, J.I. (eds.) Information Systems and Qualitative Research, pp. 469-483. Champan \& Hall (1997)

12. Quattrone, P., Hopper, T.: What is IT?: SAP, accounting, and visibility in a multinational organisation. Information and Organization 16, 212-250 (2006)

13. Hanseth, O., Monteiro, E., Hatling, M.: Developing information infrastructure: The tension between standardization and flexibility. Science, Technology \& Human Values 21, 407-426 (1996)

14. Barad, K.: Posthumanist performativity: toward an understanding of how matter comes to matter. Signs 28, 801-832 (2003)

15. Knorr Cetina, K.: Epistemic cultures: How the sciences make knowledge. Harvard University Press (1999)

16. Shapin, S., Schaffer, S.: Leviathan and the air-pump: Hobbes, Boyle and the experimental life. Princeton University Press (1985)

17. Knorr Cetina, K., Preda, A. (eds.): The sociociology of financial markets. Oxford University Press (2005)

18. MacKenzie, D., Millo, Y.: Constructing a market, performing theory: The historical sociology of a financial derivates exchange. American Journal of Sociology 109, 107-145 (2003)

19. Pettigrew, A.: Longitudinal field research on change: theory and practice. Organization Science 1, 267-292 (1990)

20. Eisenhardt, K.: Building Theories from Case Study Research. Academy of Management Review 14, 532-551 (1989)

21. Pollock, N., Williams, R.: Moving Beyond the Single Site Implementation Study: How (and Why) We Should Study the Biography of Packaged Enterprise Solutions. Information Systems Research 23, 1-22 (2011)

22. Van Maanen, J.: Qualitative studies of organizations. Sage publications (1998)

23. Langley, A.: Strategies for theorizing from process data. Academy of Management Review 24, 691-710 (1999)

24. Klein, H., Myers, M.: A Set of Principles for Conducting and Evaluating Interpretive Field Studies in Information Systems. MIS Quarterly 23, 67-93 (1999)

25. Suddaby, R.: What grounded theory is not. Academic of Management Journal 49, 633-643 (2006)

26. Frodeman, R.: Geological reasoning: Geology as an interpretive and historical science. Geological Society of America Bulletin 107, 960-968 (1995)

27. Latour, B.: Pandora's hope. Harvard University Press (1999)

28. Porter, T.: Trust in numbers: the pursuit of objectivity in science and public life. Princeton University Press (1996)

29. Ellingsen, G., Monteiro, E.: Mechanisms for producing working knowledge: enacting, orchesterating and organizing. Information and Organization 13, 203-229 (2003)

30. Nardi, B.: My Life as a Night Elf Priest: An Anthropological Account of World of Warcraft. Univ. of Michigan Press (2010) 
31. Schultze, U., Leahy, M.M.: The Avatar-Self Relationship: Enacting Presence in Second Life. In: Proc. ICIS (2009)

32. Barley, S., Kunda, G.: Bringing work back in. Organization Science 12, 76-95 (2001)

33. Perin, C.: Shouldering risks: the culture of control in the nuclear power industry. Princeton University Press (2005)

34. Weick, K., Sutcliffe, K.: Managing the unexpected: assuring high performance in an age of complexity. Jossey Bass (2001) 